\title{
BUSINESS INTELLIGENCE ADOPTION IN ACADEMIC ADMINISTRATION: AN EMPIRICAL INVESTIGATION
}

\author{
Sutee Sujitparapitaya, San Jose State University, sutee.sujitparapitaya@sjsu.edu \\ Ashraf Shirani, San Jose State University, ashraf.shirani@sjsu.edu \\ Malu Roldan, San Jose State University, malu.roldan@sjsu.edu
}

\begin{abstract}
This study contributes to research in adoption of innovation in academic administration by testing the effect of a comprehensive set of variables on adoption of business intelligence (BI) in institutions of higher education. Using data from 243 institutions, ten variables in technology, organizational, and environmental dimensions were examined. Although results were generally consistent with those for corporate organizations, there were a few unexpected findings as well: institutions of higher education were less likely to adopt BI if they were private rather than public; and instead of being a deterrent, perceived complexity of BI applications was positively related to BI adoption in academic institutions. The findings of the study, which have useful implications for practitioners and researchers, are discussed.
\end{abstract}

Keywords: Business Intelligence; Analytics; IT Adoption; Innovation Adoption; Academic Administration

\section{INTRODUCTION}

To effectively respond to the changing marketplace demands, regulatory requirements, and competitive pressures, one set of technologies and business practices that many organizations are increasingly turning to is collectively known as business intelligence. Business intelligence is often used as an umbrella term for technologies, applications, and processes for gathering, organizing, storing, reporting, and analyzing data for organizational decision support [29]. Inherent in this definition is a wide and varied list of technologies including databases, data marts and data warehouses to integrate and store data; extract, transform, and load (ETL) tools to cleanse, standardize, and load data; and tools for reporting, dashboarding, and visualization, data and text mining, predictive analytics, enterprise performance management, and decision support. Information and communication technologies, such as BI, are an integral part of the modern corporation and have profound impacts on organizational performance. Major corporations continue to focus on BI and analytics in their business expectations and planned technology outlays. The extent to which these technologies have made inroads in higher education administration, however, remains largely unknown. Although some recent research has examined corporate adoption of data warehousing, e.g., [17], few comprehensive studies have looked at the diffusion of BI technologies in higher education administration. The higher education services sub-sector is a vital pillar of the US economy. Recent estimates indicate that the US has the largest number of higher education students in the world. There were 6, 632 institutions and 25.88 million students or approximately $8.4 \%$ of the US population enrolled in higher educational institutions in academic year 2008-09 [28].

The central theme of this study is to examine the technology, organizational and environmental factors that influence adoption of BI in private and public institutions of higher education (IHE). The primary questions it seeks to answer are whether and how IHE differ from corporate organizations in adopting and deploying information technologies such as business intelligence. Since the set of technologies and software components in a typical BI architecture is often large and diverse, it is necessary to use a simplifying approach to comprehend and examine the extent of BI adoption in an organization. One common approach is to look at the overall BI landscape in terms of successive layers of components comprising, for example, of source data and ETL; integrated data in data warehouses and 


\section{Issues in Information Systems}

Volume 13, Issue 2, pp. 112-122, 2012

data marts; and end-user BI applications for reporting, mining, and business analytics [24]. The focus of the present research is on the end-user BI applications layer.

This study contributes towards research in organizational adoption of IT in general and BI in particular, in the following major ways: (1) Drawing from the extant innovation adoption literature, this study provides a comprehensive assessment of all of the significant determinants of IT adoption identified by prior research. The study examines ten key factors in three dimensions -technology, organizational, and environmental. (2) It examines innovation adoption in higher education that has not received adequate research attention. Due to important differences between institutions of higher education and corporate organizations, findings of prior innovation adoption research that has generally focused on the latter type of organizations, are re-examined for their applicability in academic institutions.

\section{LITERATURE REVIEW AND RESEARCH MODEL}

IT innovation represents an administrative or operational idea, practice, or object perceived as new and whose underlying basis is information technology [23]. Innovative technologies have been credited with endowing organizations with competitive advantage through a variety of sources ranging from operational efficiency and effectiveness to strategic decision support and visibility into their operations and supply chains. Research in organizational adoption of IT innovations has attempted to identify factors closely associated with the likelihood of adoption, and to explain why some organizations either adopt or adopt early and others don't. Business intelligence and related technologies, such as data warehousing are among the relatively recent innovations that organizations are increasingly adopting or considering to adopt.

For the purpose of this study, the following definition of BI is used [29]: "Business intelligence (BI) is a broad category of technologies, applications, and processes for gathering, storing, accessing, and analyzing data to help its users make better decisions." Adoption in this study refers to an institution's decision to accept an innovation by acquiring, implementing, or using it (e.g., [26]).

\section{BI in Academic Administration}

Prior IT innovation research has overwhelmingly been in the context of corporations -both private and publicly traded. Although what we learned through such research is indeed helpful in understanding organizational technology adoption in general, it is uncertain if the findings are equally applicable and hence of use in predicting adoption behavior in institutions of higher education. One important reason why organizations adopt innovative technologies, models, and business practices is the support they provide in accomplishing organizational objectives at strategic, tactical, and operational levels. BI supports organizational objectives in a number of ways; prominent among them are its tools and applications for reporting, electronic dashboards, predictive analytics, and visualization.

Regulatory reporting requirements: Many publicly held companies need to comply with regulatory reporting requirements such as those set by the US Securities and Exchange Commission and others mandated by the Sarbanes-Oxley Act. Similarly, IHEs are required to provide a multitude of reports to governmental and oversight agencies, and their reporting needs are continuous and ongoing. Their charters and funding sources typically obligate them to demonstrate compliance with local, state and federal laws, maintain pertinent data, and provide reports on a regular basis. Like most service organizations, accreditation is another important activity that keeps schools and colleges within IHEs busy year-round. Keeping track of continuously changing data on a large number of variables and attributes is a major challenge for most IHEs. Data warehousing and BI technologies that enable data integration from internal and external sources, help standardize attributes and terminology, and provide end user analysis and reporting tools, can be of immense help in these endeavors. An integrated data source, for example, helps provide basis for data reconciliation, reduce redundancy, and promote data integrity [14]. 


\section{Issues in Information Systems}

Volume 13, Issue 2, pp. 112-122, 2012

Student lifecycle management: IHEs cater to students in identifiable, well-defined phases in their lifecycle: prospects, applicants, admits, enrollees, and then alumni. A student may enter an IHE's database as a prospect in high school or a community college, get admitted, enroll to fulfill degree requirements, and then graduate. The student may eventually become an alumnus and possibly a donor. Data available through cohort tracking applications can enable an institution to assess its recruiting, admissions, continuing enrollment, retention/graduation, career development, and fund-raising efforts. Although student demographic attributes remain relatively stable, other attributes change dramatically from one phase to the next. Through data integration and maintenance of current as well as historical data, data warehousing and BI tools can help IHEs monitor student achievements as they progress from one phase to the next.

Fund-raising, accreditation, rankings, and other IHE specific needs: Besides concerns and activities that a typical corporation must manage in various functional areas ranging from budgeting and finance to logistics and human resources, IHEs have their specific needs for reporting and analytics. Class scheduling, recruiting, accreditation, managing institutional rankings, fund-raising, faculty scholarly and creative achievements, and research grants are some of such needs that occupy IHE administrations on a daily basis. BI tools can be of great help in supporting these tasks as well as provide visibility into campus- and multiple-campus wide operations ranging from student housing, career development, sports, and facilities to crime prevention, diversity and equal opportunity.

\section{Research Model and Hypotheses}

Although empirical research in organizational adoption of BI is relatively limited, several studies have examined adoption of various other information technologies. A meta-analysis [17], for example, reviewed findings of prior research in organizational adoption of intranets, CASE tools, object-oriented programming, e-business, executive information systems, and project management software, among others. The study identified three most frequently examined categories of determinants: organizational, environmental, and characteristics of the innovation. Innovation adoption research specific to BI and data warehousing, (e.g., [20]), along with studies of other IT innovations in recent years (e.g., [13]), support the validity of the three categories of determinants, though they point to a few additional variables as well. Using significant determinants identified by these and other studies described in the next section, we examined the impact of a comprehensive set of ten variables in three dimensions on adoption of BI in IHE. The research model is depicted in Figure 1. 


\section{Issues in Information Systems}

Volume 13, Issue 2, pp. 112-122, 2012

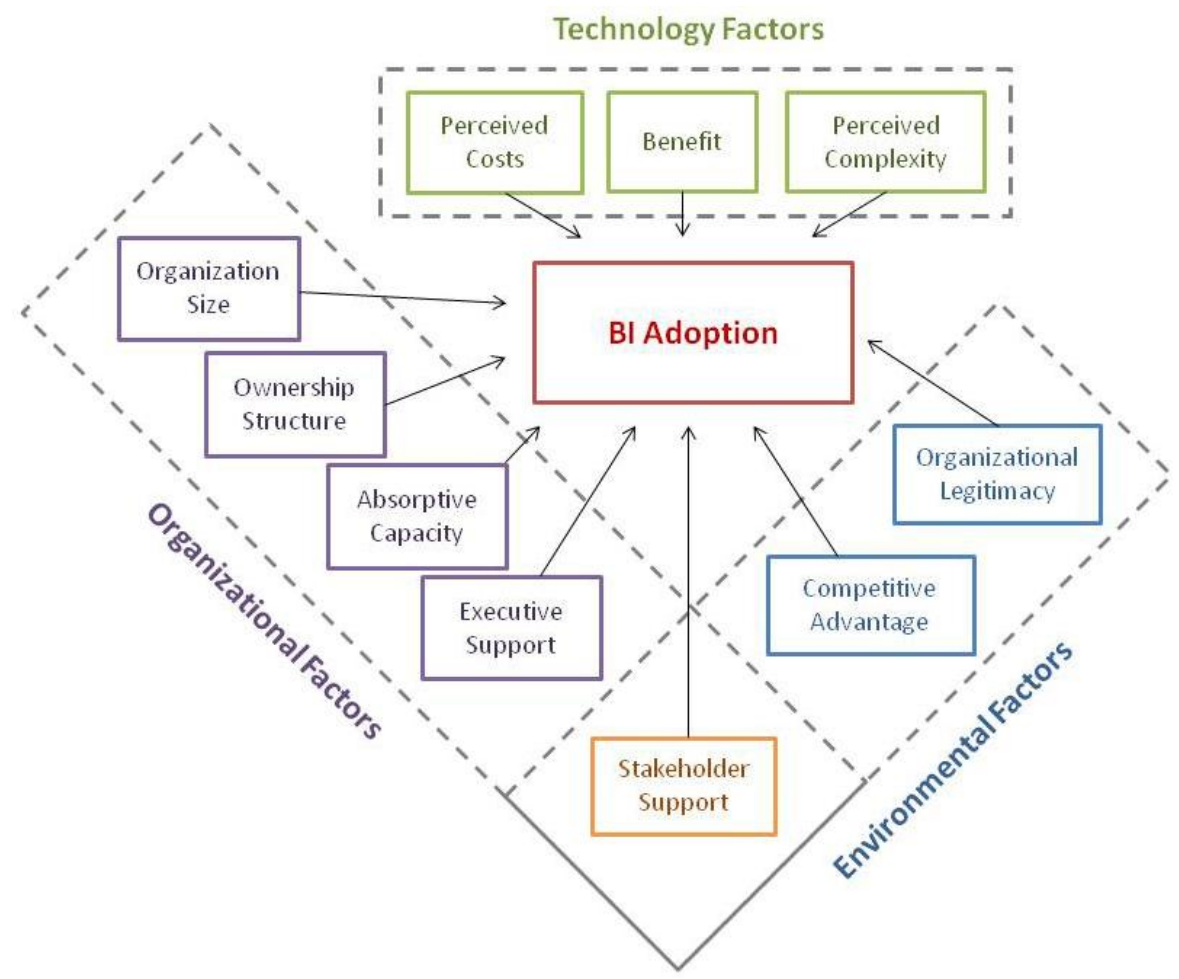

Figure1. Research Model

\section{Organizational Factors}

Ownership structure: public vs. private: Organizations are legal entities created to support the objectives of their owners and stakeholders. Significant differences in organizational, environment, and managerial practices, attributable to their ownership - i.e., public or private - can act as barriers to new managerial techniques and innovations [12]. Public organizations have less competitive pressures and are often expected to cooperate rather than compete with other organizations offering similar services. They often have many stakeholders with a variety of demands and expectations, which sometimes may be conflicting [18]. For example, tax payers may not approve of certain capital projects whereas service recipients may demand them. Data warehousing and BI investments are typically long-range and ongoing initiatives, requiring considerable amount of resources, organizational commitment, and integration into organizational processes and practices. Hence we proposed that:

H1: Private IHEs are more likely to adopt BI applications than public ones.

Organization size: The association between the size of an organization and the likelihood of its adopting innovations has been widely studied. One (minority) view is that smaller organizations tend to be more agile and productive than larger ones, particularly in their research and development endeavors, and hence are more likely to adopt innovations [31]. A more common and consistent research finding, however, is that large firms often have more resources and are better prepared at mobilizing them to acquire and utilize innovative practices and technologies [20]. Large organizations often have more capital reserves to offset any setbacks. Large organizations benefit from economies of scale and hence costs of innovations are proportionally less for larger organizations, providing incentives for them to innovate [7]. Also, due to their diverse operations, new innovations are often complimentary to a variety of their existing activities and hence more beneficial to them than they are to small organizations [11]. 


\section{Issues in Information Systems}

Volume 13, Issue 2, pp. 112-122, 2012

BI initiatives and their supporting infrastructure, such as data warehouses and data marts, are resource-intensive in terms of both capital and skilled labor, which large organizations are generally better prepared to muster. Recent empirical research examining data warehouse implementations has confirmed that organization size is positively related to adoption (e.g., [20]). It is therefore proposed that:

$\mathrm{H} 2$ : Institution size is positively related to BI adoption.

Absorptive capacity: Organizational absorptive capacity, which refers to "the ability of a firm to recognize the value of new, external information, assimilate it, and apply it to commercial ends", is considered essential to organizational innovative capabilities [5]. Research has generally established that absorptive capacity is a significant antecedent of organizational innovation. For innovations in information technologies and systems, absorptive capacity has been interpreted as the knowledge and skills of an organization's employees along with relevant strategic and operational activities and business processes. Consistent with most prior research, an empirical study [20] found that absorptive capacity was positively related to data warehousing adoption. Hence we proposed:

H3: Absorptive capacity is positively related to BI adoption.

Executive support: BI and data warehousing projects are often enterprise-wide initiatives, impact large segments of organizational workforce, and entail long-term financial and human resource commitment. BI applications typically require enterprise-wide data sharing and are used to implement business process changes and enterprise performance management policies, which can be difficult to put into practice without executive support [16]. We therefore proposed that:

H4: Executive support is positively related to BI adoption.

\section{Environmental Factors}

Organizational legitimacy: Unlike competitive pressures on organizations by their competitors and substitute products and services, which force them to adopt new technologies and managerial practices, some institutional theorists suggest that legitimacy-related factors also help explain why organizations adopt new technologies. The concept of organizational legitimacy refers to organizations' desire to be accepted within their external environment [22]. The theory of organizational isomorphism suggests that organizations tend to adopt business processes and strategies that other organizations have already adopted [10]. They do so for organizational legitimacy as well as to reduce uncertainty and risk, and hence financial and strategic costs associated with new endeavors. One type of organizational isomorphism, mimetic isomorphism, implies that over time, organizations become similar to other organizations in their external environment. Prior empirical research examining the influence of mimetic isomorphism on organizational adoption of information technologies has generally established that a positive relationship exists between the two. For example, practices of peer organizations in the banking industry were found to be influential in organizational decisions to outsource their information systems [2]. Therefore, we proposed that:

H5: Organizational legitimacy is positively related to BI adoption.

Competitive advantage: BI applications have been credited with helping organizations achieve operational, tactical, and strategic decision support objectives. Wixom and Watson [29] cite a number of specific examples of how deployment of BI applications are being used to save on cost and time, improve business processes, provide timely and better information, make better decisions, and support strategic business objectives. Prior research suggests that competitive pressures influence adoption of IT innovations [15, 32]. Early adopters may be attracted to economic benefits through performance improvement and productivity gains facilitated by new technologies and practices. However, many follower organizations adopt the same technologies due to competitive pressures, thus "setting into motion a competitive bandwagon [1]. Hence we proposed that:

H6: Competitive advantage is positively related to BI adoption. 


\section{Issues in Information Systems}

Volume 13, Issue 2, pp. 112-122, 2012

Stakeholder support: Stakeholders are the raison d'être for organizations: primary constituents -owners, shareholders, and employees work towards their organizations' continued existence and prosperity, while customers provide needed financial resources by paying for goods and services. A host of other stakeholders also impact an organization's operations and investment decisions including public agencies and governments, regulators, suppliers, and rivals [3]. For academic institutions, major stakeholders include students; departmental, college, and university level administrative units; accreditation agencies; and state and federal governments and oversight agencies. As the research model in Figure 1 indicates, for this study both internal and external stakeholders are considered together as a single variable.

Adopting innovations and investing in new technologies such as BI can help organizations enhance their performance and perceived image. When organizations make strategic choices about deploying resources, they send signals to their external stakeholders, which in turn, help enhance their reputation and perceived quality of their products and services [21]. Key stakeholder support and buy-in is essential for adoption and successful deployment of innovations [20]. We therefore proposed that:

H7: Stakeholder support is positively associated with BI adoption.

\section{Technology Factors}

Perceived costs: Costs associated with acquiring, implementing, and utilizing information systems and technologies can act as a deterrent in an organization's technology adoption decisions [13]. BI and data warehousing projects are not considered specific applications or technologies; rather they form the infrastructure for wide-ranging organizational initiatives with multiple stakeholders. Thus, in addition to typically high direct costs of acquisition and operation of data warehousing and BI technologies, organizations need to commit to ongoing efforts and invest in pertinent applications and workforce so as to take advantage of the BI/DW infrastructure (e.g., [20]).

Innovation cost has been widely studied as a possible determinant of adoption [30]. It has been found to be negatively associated with adoption [8]. It is, therefore, proposed that:

H8: Perceived costs of BI applications are negatively related to BI adoption.

Perceived Benefits: For this study, perceived benefit refers to the extent to which an innovation is perceived to be better than the one it replaces [23]. A number of innovation diffusion studies have found perceived benefit of a technology positively related to its adoption [27]. It is, therefore, proposed that:

H9: Perceived benefit of BI applications is positively related to BI adoption.

Perceived complexity: Complexity refers to the level of difficulty in understanding and using an innovation [23]. Complexity of information systems has been described in terms of level of effort necessary to program, build, implement, and use such systems [19]. Diversity in a system's platforms and underlying technologies, data and information sources, and communication infrastructure require large integration efforts and thus add to their complexity. Level of complexity has been suggested as a determinant of innovation adoption [6, 23], and found to be negatively associated with data warehousing adoption [20]. BI and data warehousing systems and applications are often multi-layer and complex enterprise-wide initiatives. It is, therefore, proposed that:

H10: Perceived complexity of BI applications is negatively related to BI adoption.

\section{RESEARCH METHODOLOGY}

Survey respondents were asked to indicate their level of agreement with statements on some of the independent variables on a Likert scale; other variables were measured using multiple choice and open-ended questions. 


\section{Issues in Information Systems}

Volume 13, Issue 2, pp. 112-122, 2012

Dependent variable: BI Adoption: It was measured using one multiple choice question which asked respondents to indicate whether or not their institution was currently using BI applications. Respondents who answered yes were also asked to identify the BI application in use. This item was adopted from [15].

Independent variables: Each of the ten independent variables is described below.

Ownership structure was measured using a multiple choice question that asked respondents to indicate whether their institutions were public or private [17]. Institution size in full time equivalent (FTE) was obtained from the U.S. Dept. of Education web site [28]. Organization absorptive capacity was measured by asking respondents for their level of agreement with statements regarding key users' familiarity with and vision for BI applications in their institution, key users' technical sophistication, and the capabilities of their IT infrastructure and staff [20]. Executive support was measured by asking respondents how crucial senior management support was to the success of BI adoption and how supportive their senior management had been of BI adoption in their institution [16]. Organizational legitimacy was measured by asking respondents if their BI adoption was influenced by competitors, success of BI adoption by other institutions, or because BI adoption was viewed favorably by other institutions [25]. Competitive advantage was measured using one question asking respondents the extent to which BI tools help increase their institutions' competitiveness [25]. Stakeholder support was measured by asking respondents whether BI and related technologies are perceived favorably by constituents and stakeholders. Perceived complexity was measured using three questions asking the respondents whether complexity of BI applications was a factor in the difficulty of learning, installing, operating, and maintaining BI applications [9, 20]. Perceived cost of BI implementation was measured by asking respondents whether the BI tools to facilitated reporting and analysis at a lower cost. Perceived benefits were measured using four questions that focused on the benefits and positive impact of BI tools on their organization's decision support capabilities, reporting efficiency, competitiveness, and effectiveness in meeting deadlines and budget targets. These items were adopted from [20] and [13].

\section{Survey Design and Data Collection}

The survey instrument was developed by adapting items from published literature on organizational innovation adoption. After completion of the initial draft questionnaire, three institutional researchers were asked to examine and assist in modifying the questionnaire content. Subsequently, three IS faculty were invited to examine the questionnaire to ensure clarity and relevance of items. Feedback from the institutional researchers and IS faculty helped shape the final version of the questionnaire. Subjects of this study were senior administrators of institutional research and information technology units at both two- and four-year institutions. An online invitation along with a unique Web address to the questionnaire was sent to 1,592 unit heads. An email reminder was sent two weeks after the initial survey request. Participants were offered an incentive. A total of 250 responses were received showing an overall response rate of $16 \%$. However, 243 responses were usable and seven incomplete responses were eliminated.

The descriptive statistics indicate that $56 \%$ of the respondents were BI adopters. Of those, $27 \%$ had more than 5 years, 38\% had between 2 and 5 years, and 35\% had less than 2 years of experience with BI applications. The majority of responses (75\%) came from 4-year institutions, and $25 \%$ came from 2-year institutions. The institutions' Full-time Equivalent (FTE) enrollment was used to determine the size of the institutions [4]. In terms of size, $42 \%$ of the participants were from large, 28\% from medium-sized, and 30\% from small and very small institutions.

\section{RESULTS}

The results in Table 1 indicate that seven of the ten study variables - organization structure, institution size, absorptive capacity, organizational legitimacy, stakeholder support, perceived costs, and perceived complexity emerged as significant determinants of BI adoption in IHE. Three variables - executive support, competitive advantage, and perceived benefits - had no significant effect. Perhaps most interesting are the findings pertaining to two variables -organization structure and perceived complexity of BI applications; the results were significant, though in the direction opposite to that postulated. Contrary to the expectation based on findings of the past 


\section{Issues in Information Systems}

Volume 13, Issue 2, pp. 112-122, 2012

innovation adoption research in corporate organizations, institutions of higher education are less likely to adopt BI if they are private rather than public. And instead of being a deterrent, perceived complexity of BI applications is positively related to BI adoption in academic institutions. It is also important to note that although executive support is considered a significant determinant of adoption of data warehousing and related technologies in corporate organizations, it was not found to be significant in academic institutions.

Table 1. Logistic Regression Model Results

\begin{tabular}{|l|l|l|l|}
\hline $\begin{array}{l}\text { Research } \\
\text { model relationship }\end{array}$ & $\begin{array}{l}\text { Logistic coefficient } \\
\text { (standard error) }\end{array}$ & $\begin{array}{l}\text { Wald statistic } \\
\text { (significance level) }\end{array}$ & Support for Model \\
\hline Organization Structure & $-.739(.276)$ & $7.202^{*}$ & $\begin{array}{l}\mathrm{H}_{1}: \text { No. Significant in the } \\
\text { opposite direction }\end{array}$ \\
\hline Institutions Size & $.319(.124)$ & $6.593^{* * *}$ & $\mathrm{H}_{2}:$ Yes \\
\hline Absorptive Capacity & $.339(.186)$ & $3.327^{* * *}$ & $\mathrm{H}_{3}:$ Yes \\
\hline Executive Support & $.291(.224)$ & 1.678 & $\mathrm{H}_{4}:$ No \\
\hline Organizational Legitimacy & $.511(.277)$ & $3.405^{* * *}$ & $\mathrm{H}_{5}:$ Yes \\
\hline Competitive Advantage & $-.381(.262)$ & 2.119 & $\mathrm{H}_{6}:$ No \\
\hline Stakeholder Support & $.486(.280)$ & 3.016 & $\mathrm{H}_{7}:$ No \\
\hline Perceived Costs & $-.512(.298)$ & $2.952^{* * *}$ & $\mathrm{H}_{8}:$ Yes \\
\hline Perceived Benefits & $-.240(.280)$ & .736 & $\mathrm{H}_{9}:$ No \\
\hline Perceived Complexity & $.417(.204)$ & $4.167^{* *}$ & $\begin{array}{l}\mathrm{H}_{10}: \text { No. Significant in the } \\
\text { opposite direction }\end{array}$ \\
\hline
\end{tabular}

* Significant at $0.01 \quad * *$ Significant at $0.05 \quad * * *$ Significant at 0.10

\section{DISCUSSION AND IMPLICATIONS}

For adopting and deploying enterprise information technologies such as business intelligence, the study results, overall, indicate that academic institutions are alike as well as markedly different from corporate organizations. Consistent with past findings in corporate organizations, several variables showed statistically significant association with adoption. Findings of the study also indicate a few differences between the two types of organizations that may have important implications for practice and future research.

Organization Structure: Contrary to expectations, the study findings support the relationship opposite to that hypothesized. The study results show that public - rather than private - IHEs are more likely to adopt BI applications. This is somewhat surprising since large investments and ongoing expenses in BI are generally incompatible with the cyclical nature of funding for public IHEs. One possible explanation may be that heightened reporting requirements and budgetary constraints are perhaps prompting public universities to increasingly adopt BI reporting and analytical tools to support their operational requirements and strategic goals in matters ranging from enrollment forecasts to digital dashboards to garner stakeholder support and provide visibility into their accomplishments. Future research may help confirm this postulation.

Organization Size: As expected, IHE size was positively associated with BI adoption. Although smaller organizations may benefit from their ability to be agile [31], the large amount of resources and investment often necessary for BI adoption tend to favor large organizations, particularly because their surplus resources allow them to mitigate risks inherent with innovations [20].

Absorptive Capacity: This study lends further empirical support to the notion (e.g., [20]) that absorptive capacity an organization's capability in terms of knowledge and skills -is a necessary condition for successful adoption and 


\section{Issues in Information Systems}

Volume 13, Issue 2, pp. 112-122, 2012

exploitation of new and complex technologies. Such capability, coupled with other requisite resources, is a key indicator of an organization's readiness to implement BI projects.

Organizational Legitimacy: The study findings also indicate organizational legitimacy as a significant determinant of BI adoption. Organizations often adopt technologies not only because they have the resources and internal knowhow to do so effectively but also because of an imperative to align themselves with their competitors and partners $[2,25]$. As BI becomes an accepted practice in many industries as well as academic institutions, accrediting bodies, and funding agencies, IHEs will increasingly seek to implement BI in order to gain legitimacy among their peers and other members of their external environment.

Perceived Cost: Consistent with most prior findings (e.g., [8, 30]), cost was found to be a strong deterrent to adoption of BI. BI applications not only require large upfront investments in infrastructure, technology, and manpower, but also significant outlays for maintenance and operations, particularly if an organization seeks to fully exploit BI capabilities throughout the organization and for its strategic advantage [20]. An IHE whose financial resources do not meet the financial threshold may consider delaying large-scale BI initiatives and explore alternatives including open source technologies.

Perceived Complexity: A second surprising result of this study is that contrary to most past research findings, complexity of BI applications was found to be positively - rather than negatively - related to adoption. Institutions that adopted BI were more likely to perceive BI as a complex technology. Two possible explanations can be offered. First, BI has become a business imperative and legitimized enough in the IHEs and other organizations that complexity is a secondary consideration in the adoption decision. Since BI is now often considered essential to operational efficiency and strategic decision support in the industry, IHEs adopt the technology despite its complexity and large resource requirements. Second, BI, like most other enterprise technologies, tends to be perceived more complex after it is deployed and incorporated in organizational work and business processes. That is, it would be more accurate to view technology complexity as a lagging, rather than a leading indicator of BI adoption. Future research may examine this hypothesis.

Other Findings: Future research may help explicate non-significance of findings for the four variables - executive support, competitive advantage, stakeholder support, and perceived benefits. Shift in relative emphasis on internal stakeholders and technology versus environmental factors, may partially explain some of these findings. BI technologies have been used in various industries for many years and have been classified as mainstream by industry and technology observers. Furthermore, external entities that have a stake in IHE's operational efficiency and strategic management, such as accrediting bodies and government reporting and funding agencies, require that IHE's implement more data-driven management and reporting. As a result, decisions to deploy BI are often made on the need to align with the expectations of external stakeholders rather than rely solely on internal stakeholders and executive support. Though executive support remains crucial in facilitating adoption of relatively new and untested technologies, such support is perhaps not as important for technologies such as BI that are beyond the infancy stage in their lifecycle. Future research may look at internal and external stakeholders, separately, unlike this study in which they were grouped together.

\section{CONCLUSIONS}

In terms of variables influencing organizational decisions to adopt BI, although there are a few important differences between IHE's and corporate organizations, they are more alike than different, overall. While factors associated with an organization's ability to invest in resources and capabilities to implement BI were found to be significant, the effects of factors traditionally associated with innovation adoption - perceived benefits of the technology, executive support, competitive advantage, and perceived complexity -were either not significant or were in the direction opposite to that posited based on past research. The findings suggest that organizational legitimacy and absorptive capacity were among the important variables that were positively associated with BI adoption in IHEs. The diffusion of BI across IHEs is also helped by vendor experience with the early adopter organizations in other industries. Prolonged vendor's and technical consultant's experience, in turn, has helped mitigate some of the implementation 


\section{Issues in Information Systems}

Volume 13, Issue 2, pp. 112-122, 2012

complexity and build confidence among new IHE adopters. Major BI vendors and third-party consultants have accumulated valuable knowledge bases containing implementation procedures, models, and proofs of concepts to help IHEs make informed adoption decisions.

One limitation of this study is that adoption was measured with a binary variable, in line with earlier studies of innovation adoption [20]. Unfortunately, this approach limits our ability to fully discern the dynamics among the antecedents and BI adoption decisions. Since the binary variable does not capture the extent to which BI is adopted by an organization, it is not possible to determine if the influence of the independent variables is different at different levels of implementation.

\section{REFERENCES}

1. Abrahamson, E., \& Rosenkopf, L. (1993). Institutional and competitive bandwagons: Using mathematical modeling as a tool to explore innovation diffusion. Academy of Management Review, 18, 487-517.

2. Ang, S., \& Cummings, L. (1997). Strategic response to institutional influences on informational systems outsourcing. Organizational Science, 8(3), 235-256.

3. Buysse, K., \& Verbeke, A. (2003). Proactive environmental strategies: a stakeholder management perspective. Strategic Management Journal, 24(5), 453-470.

4. Carnegie Foundation for the Advancement of Teaching (2010). Classification Description: Size, Setting Classification. Retrieved August 14, 2011, from http://classifications.carnegiefoundation.org/descriptions/size_setting.php

5. Cohen, W. M., \& Levinthal, D. A. (1990). Absorptive capacity: a new perspective on learning an innovation. Administrative Science Quarterly, 35(1), 128-152.

6. Cooper, R., \& Zmud, R. (1990). Information technology implementation research: A technological diffusion approach. Management Science, 36(2), 123-139.

7. Damanpour, F. (1991). Organizational innovation: a meta-analysis of effects of determinants and moderators. Academy of Management Journal, 34(3), 555-590.

8. Damanpour, F., \& Schneider, M. (2008). Characteristics of Innovation and Innovation Adoption in Public Organizations: Assessing the Role of Managers. Journal of Public Administration Research and Theory, 19, 495-522.

9. Davis, F. (1989). Perceived usefulness, perceived ease of use and user acceptance of technology. MIS Quarterly, 13(3), 319-339.

10. Deephouse, D. L. (1996). Is isomorphism legitimate? Academy of Management Journal, 39(4), 1024-1039.

11. Geroski, P. (2000). Models of technology diffusion. Research Policy, 29, 603-625.

12. Heintze, T., \& Bretschneider, S. (2000). Information Technology and Restructuring in Public Organizations: Does Adoption of Information Technology Affect Organizational Structures, Communications, and Decision Making? Journal of Public Administration, Research \& Theory, 10(4), 801-830.

13. Hung, S.-Y., Hung, W.-H., Tsai, C.-A., \& Jiang, S.-C. (2010). Critical factors of hospital adoption on CRM system: Organizational and information system perspectives. Decision Support Systems, 48, 592-603.

14. Inmon, W., Strauss, D., \& Neushloss, G. (2008). DW 2.0: The Architecture for the Next Generation of Data Warehousing. Burlington, MA: Morgan Kaufmann.

15. Kennedy, M. T., \& Fiss, P. C. (2009). Institutionalization, framing, and diffusion: The logic of TQM adoption and implementation decisions among U.S. hospitals. Academy of Management Journal, 52(5), 897-918.

16. Law, C., \& Ngai, E. (2007). ERP systems adoption: An exploratory study of the organizational factors and impacts of ERP success. Information \& Management, 44, 418-432.

17. Lee, G., \& Xia, W. (2006). Organizational size and IT innovation adoption: A meta-analysis. Information \& Management, 43, 975-983.

18. Metcalfe, L. (1993). Public management: from imitation to innovation. In J. Kooiman (Ed.), Modern Governance. London: Sage.

19. Meyer, M. H., \& Curley, K. F. (1991). An applied framework for classifying the complexity of knowledgebased systems. MIS Quarterly, 15, 455-475.

20. Ramamurthy, K., Sen, A., \& Sinha, A. (2008). An empirical investigation of the key determinants of data 


\section{Issues in Information Systems}

Volume 13, Issue 2, pp. 112-122, 2012

warehouse adoption. Decision Support Systems, 44, 817-841.

21. Rindova, V. P., Williamson, I. O., Petkova, A. P., \& Sever, J. M. (2005). Being good or being known: an empirical examination of the dimensions, antecedents, and consequences of organizational reputation. Academy of Management Journal, 48(6), 1033-1049.

22. Roberts, P. W., \& Greenwood, R. (1997). Integrating transaction cost and institutional theories: Toward a constrained-efficiency framework for understanding organizational design doption. Academy of Management Review, 22(2), 346-373.

23. Rogers, E. M. (2003). Diffusion of innovations (5 ed.). New York: The Free Press.

24. Shirani, A., \& Roldan, M. (2009). Data warehousing and business intelligence skills for information systems graduates: Analysis based on marketplace demand. Issues in Information Systems, 10(2), 333-339.

25. Son, J.-Y., \& Benbasat, I. (2007). Organizational Buyers' Adoption and Use of B2B Electronic Marketplaces: Efficiency- and Legitimacy-Oriented Perspectives. Journal of Management Information Systems, 24(1), 55-99.

26. Straub, E. T. (2009). Understanding Technology Adoption: Theory and Future Directions for Informal Learning. Review of Educational Research, 79(2), 625-649.

27. Tornatzky, L. G., \& Klein, K. (1982). Innovation characteristics and innovation adoption implementation: metaanalysis of findings. IEEE Transactions on Engineering Management, 29(11), 28-45.

28. U.S. Dept. of Education (2009). Number and percentage distribution of Title IV institutions, by control of institution, degree-granting status, and highest level of offering: United States, academic year 2008-09. Retrieved August 18, 2011, from http://nces.ed.gov/das/library/tables_listings/ipeds2008.asp

29. Wixom, B., \& Watson, H. (2010). The BI-Based Organization. International Journal of Business Intelligence Research, 1(1), 13-28.

30. Wolfe, R. A. (1994). Organizational innovation: Review, critique, and suggested research directions. Journal of Management Studies, 31, 405-431.

31. Yeaple, R. N. (1992). Why are small R\&D organizations more productive? IEE Transactions on Engineering Management, 39(4), 332-346.

32. Zhu, K., Kraemer, K. L., \& Xu, S. (2006). The process of innovation assimilation by firms in different countries: A technology diffusion perspective on e-business. Management Science, 52(10), 1557-1576. 